\title{
Internal melt figures in ice by rapid adiabatic compression
}

\author{
R. E. GAGNON, \\ Institute for Marine Dynamics, National Research Council of Canada, St. John's, Newfoundland A1B 3T5, Canada \\ C. TUlK AND H. KiefTe \\ Department of Physics, Memorial University of Newfoundland, St. John's, Newfoundland A1B 3X7, Canada
}

\begin{abstract}
Single crystals and bicrystals of water ice have been adiabatically pressurized to produce, and clearly illustrate, two types of internal melt figures: (1) dendritic figures that grow from nucleation imperfections on the specimen's surface, or from air bubbles at grain boundaries, into the ice as pressure is elevated; and (2) compression melt fractures, flat liquid-filled disks, that nucleate at imperfections in the crystal and grow with the application of pressure eventually to sprout dendritic fingers at the periphery. The transparency of the ice permitted visualization of the growth and behavior of the figures, and this could be an important tool in understanding the role of phase transformations in deep-focus earthquakes. Correlation between figure size and pressure is noted for the first time.
\end{abstract}

\section{INTRODUCTION}

Internal melt figures, first reported by John Tyndall (1858), form in ice and other substances (McLaurin and Whalley, 1988) when they melt internally. In the laboratory, internal melt figures have been formed in ice by infrared irradiation, dielectric heating and rapid adiabatic compression (Kaiser and Magun, 1964; Baumann and others, 1984). Melting occurs internally by conduction of heat to nucleation sites from the surrounding superheated ice. For slow rates of energy input, the figures form in the shape of flat disks or hexagonal plates with a vapor bubble present, whereas for rapid energy input figures are highly dendritic. Compression melt fractures (Knight and Knight, 1972), i.e. flat liquid-filled disks without a vapor bubble, can also form by rapid energy input. Here, we report clear observations of dendritic melt figures and compression melt fractures formed by adiabatic compression and we note the possible importance of this method to the study of deep-focus earthquakes.

\section{APPARATUS}

A high-pressure vessel (Gagnon and others, 1988) was used hydrostatically to pressurize small samples $\left(\sim 150 \mathrm{~mm}^{3}\right)$ cut from single crystals and bicrystals of ice grown from filtered de-ionized and degassed water. A microscope and video camera were used to record the behavior of the specimens through one of the windows (2.2 $\mathrm{mm}$ diameter) of the pressure vessel. A hand-pump fitted with a Heise pressure gauge was used to pressurize the vessel up to $2 \mathrm{kbar}$ in $\sim 300$ bar increments at rates up to $\sim 1.2 \mathrm{kbar} \mathrm{s}^{-1}$ per stroke.

\section{OBSERVATIONS}

During pressurization of a typical mono-crystalline specimen, tiny surface scratches and asperities from the sample preparation quickly melted when the phaseboundary pressure was reached. Etch pits, which also quickly melted away, were sometimes observed on the surface as the critical pressure was attained. Further application of pressure resulted in nucleation of dendritic fern-like melt figures at the surface that grew into the ice at a rate proportional to the rate of pressure application (Fig. 1). Figures were stable in size when pressure was static though the faceted and sharp-edged surface features became rounded as heat conducted from the surrounding ice and resulted in a slight thickening of the figure just after each pressure increment with the hand-pump. Relieving the pressure reversed the growth process and caused the figures to shrink at a rate proportional to the rate of decompression. Advancing dendrites were very thin $(\sim 20 \mu \mathrm{m})$. They grew primarily parallel to the basal plane and they would often have offshoots in planes normal to the basal plane (Fig. 2) and occasionally at other angles to the basal plane.

Pressurization of bicrystals with air bubbles $(<40 \mu \mathrm{m})$ at the grain boundary exhibited a similar behavior. Melting at the boundary would occur at the critical pressure and liquid would fill the air-bubble cavities. As 

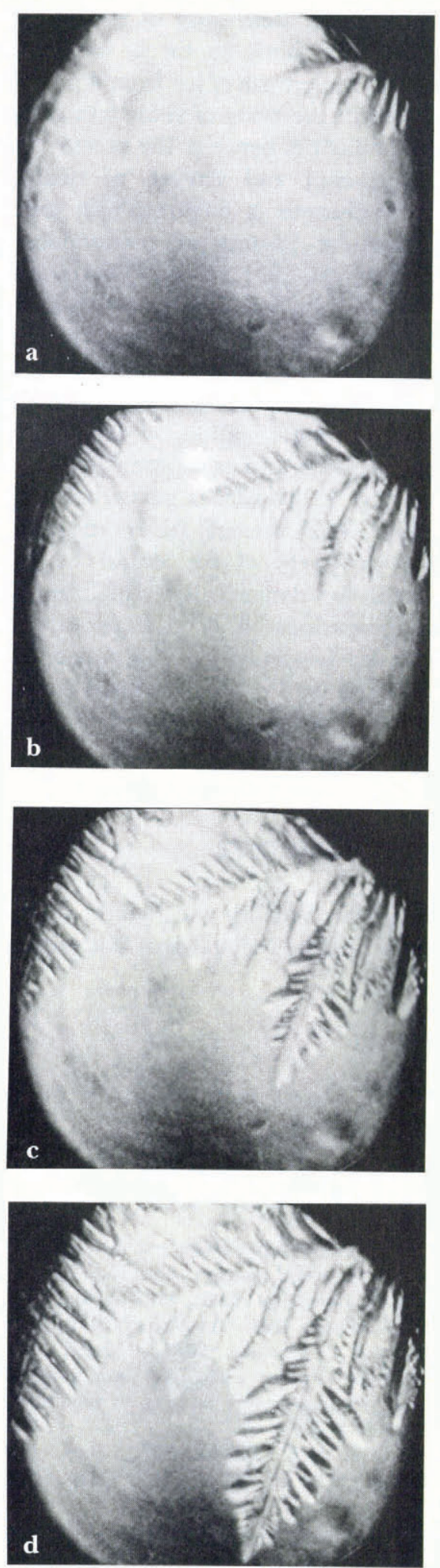

Fig. 1. Growth of a dendritic melt figure parallel to the basal plane as pressure was elevated during one stroke of the hand pump. The increments in time and pressure between consecutive images are $1 / 15 \mathrm{~s}$ and 26 bar, respectively. The diameter of the circular aperture is $\sim 2.2 \mathrm{~mm}$. The ambient temperature was $-5^{\circ} \mathrm{C}$.

the pressure increased, dendritic figures would then nucleate from the pockets of liquid and air, and grow into the ice primarily in the basal plane of each crystal. The same behavior was exhibited by a plane of tiny air

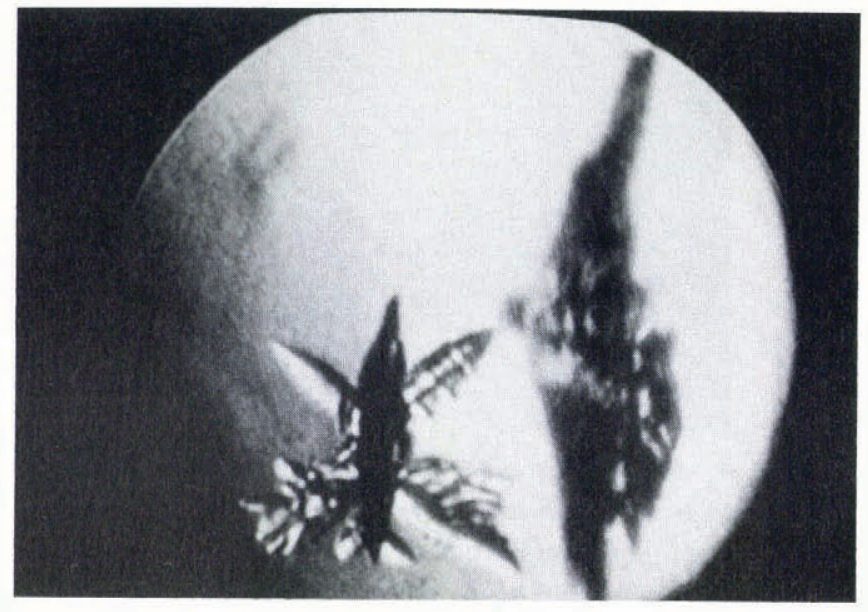

Fig. 2. A dendritic melt figure (lower left) growing from a nucleation site on the far surface of the ice sample. The central vertically oriented finger of the figure is in the basal plane and points towards the viewer. The four offshoots are at $\sim 45^{\circ}$ to the c-axis in a plane perpendicular to the basal plane. The larger, out of focus, figure on the right nucleated on the near face of the specimen. The diameter of the circular aperture is $\sim 2.2 \mathrm{~mm}$. The ambient temperature was $-12^{\circ} \mathrm{C}$.

bubbles $(<40 \mu \mathrm{m})$ in a single crystal, produced by the passage of a thin warm wire.

Decompression caused the melt figures to shrink and disappear, sometimes leaving behind many tiny $(<20 \mu \mathrm{m})$ spherical water inclusions (also noted by Baumann and others (1984)), resulting from entrapment of pressurized liquid water in the refreezing process. These outlined the shapes that figures had prior to decompression (Fig. 3). Oil inclusions, much larger in size, were present in the ice in the areas where the figures opened at the surface of the sample. Re-application of

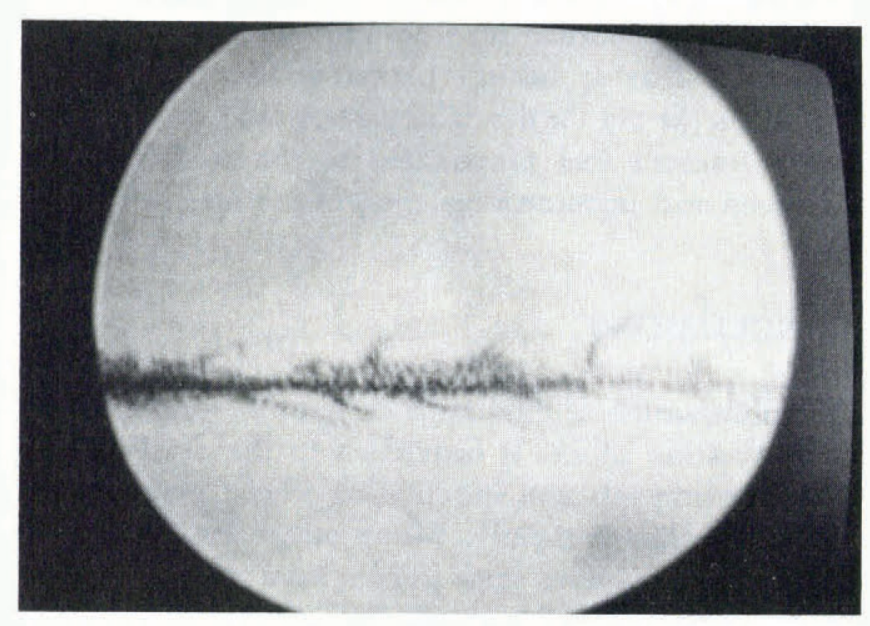

Fig. 3. Tiny spherical liquid-water inclusions outlining the shape that a dendritic melt figure had prior to decompression. The figure had grown from the left from one of the air-bubble pockets in a plane of bubbles (out of view) created, in a single crystal, by passage of a thin warm wire. The diameter of the circular aperture is $\sim 1.0 \mathrm{~mm}$. The ambient temperature during pressurization of the sample was $-12^{\circ} \mathrm{C}$. 


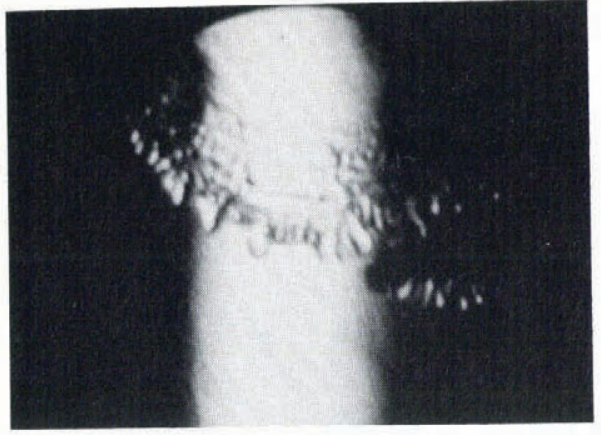

Fig. 4. Dendritic growth sprouting from the periphery (curved feature in the central region and upper half of the photograph) of a compression melt fracture as pressure was elevated. Only a part of the fracture's periphery is visible. Growth is downward in the plane of the page. A separate dendritic melt figure grew horizontally from the right. The light vertical column is an artifact of the lighting system and its width represents $\sim 0.7 \mathrm{~mm}$. The ambient temperature was $-10^{\circ} \mathrm{C}$.

pressure caused figures to re-appear at the same sites but their shapes were altered due to disruptions in the crystal lattice from the previous growth and refreezing.

Disk-shaped, liquid-filled compression melt fractures were also created by the adiabatic pressurization. In contrast to the dendritic figures, these nucleated in the crystal matrix when a certain degree of superheating had been reached and rapidly grew to a maximum size within the time span of one video frame $(1 / 30 \mathrm{~s})$, independently of the rate of pressurization. These thin $(<20 \mu \mathrm{m})$ fractures then healed at the periphery to some extent, thereby shrinking and thickening slightly to a stable smaller size within the span of a few video frames. Once formed, the fractures grew again along the healed plane upon the further application of, and in proportion to, pressure until dendritic growth initiated at the periphery when its former maximum size was reached at the end of the healed zone (Fig. 4). Compression-melt fractures shrank in proportion to the rate of decompression, sometimes leaving behind planes of tiny liquid-water inclusions (as did the dendritic figures) and oil inclusions if the fracture had propagated to the surface of the specimen and permitted the entry of pressure fluid.

\section{CONCLUSIONS}

The observation of internal melt figures, resulting from pressurization of ice, is important to the study of ice/ structure impacts and indentation where pressures are high and change rapidly. Many other crystals such as gallium, germanium and silicon have melts that are denser than the solid phase and should also develop internal melt figures as a result of pressurization near the melting temperature. Refreezing of surface melt during decompression was found to be a useful method for controlled dendritic growth of ice from liquid. This could be a useful tool in the study of snowflake growth. There are striking similarities between the present observations and the nucleation and growth of spinel (possibly superplastic) inclusions in olivine which cause faulting during mechanical loading of metastable $\mathrm{Mg}_{2} \mathrm{GeO}_{4}$ (Burnley and others, 1991). It has been postulated that the same mechanism operating in down-going slabs of lithosphere causes deep-focus earthquakes (Burnley and others, 1991). The ice I $\rightarrow$ II transformation in pressurized samples of ice jacketed with soft indium, which yields a replica of the transformation on the sample's surface after testing, has been used as an analogue for geophysical processes related to deep-focus earthquakes (Kirby and others, 1991). The present study suggests that the transparent property of ice could be a powerful additional tool for dynamically visualizing the role of phase transformations in deep-focus earthquakes by observing the ice $\mathrm{I} \rightarrow$ liquid transformation, and possibly the ice I $\rightarrow$ II and ice I $\rightarrow$ III solid-solid transformations, in single crystals and at grain boundaries under various loading conditions.

\section{ACKNOWLEDGEMENTS}

We thank Dr E. Whalley for helpful discussions and encouragement at the beginning of this project.

\section{REFERENCES}

Baumann, K., J. H. Bilgram and W. Känzig. 1984. Superheated ice. Z. Phys. B, 56(4), 315-325.

Burnley, P. C., H.W. Green II and D. J. Prior. 1991. Faulting associated with the olivine to spinel transformation in $\mathrm{Mg}_{2} \mathrm{GeO}_{4}$ and its implications for deep-focus earthquakes. 7. Geophys. Res., 96(B1), $425-443$.

Gagnon, R. E., H. Kiefte, M.J. Clouter and E. Whalley. 1988. Pressure dependence of the elastic constants of ice Ih to $2.8 \mathrm{kbar}$ by Brillouin spectroscopy. J. Chem. Phys., 89(8), 4522-4528.

Kaiser, G. and S. Magun. 1964. Schmelzvorgänge in Eiskristallen unter erhöhtem Druck. Z. Kristallogr., 120(6), 450-465.

Kirby, S.H., W.B. Durham and L.A. Stern. 1991. Mantle phase changes and deep-earthquake faulting in subducting lithosphere. Science, 252, 216-225.

Knight, C. A. and N. C. Knight. 1972. Superheated ice: true compression fractures and fast internal melting. Science, 178(4061), 613-614.

McLaurin, G. E. and E. Whalley. 1988. Negative octahedral snowflakes or Tyndall figures in tetrahydrofuran clathrate hydrate. Nature, 332(6166), 711-712.

Tyndall, J. 1858. On some physical properties of ice. Proc. R. Soc. London, Ser. A., 9, 76-80.

The accuracy of references in the text and in this list is the responsibility of the authors, to whom queries should be addressed. 